\title{
In vitro Evaluation of Botanicals against Alternaria cyamopsidis causing Alternaria blight of Clusterbean
}

\author{
Manasa Yedida* and Reeti Singh \\ Department of Plant Pathology, Rajmata Vijayaraje Scindia Krishi Vishwavidyalaya, \\ Gwalior-474002, (M.P.), India \\ *Corresponding author
}

\section{A B S T R A C T}

Keywords

Alternaria cyamopsidis, Clusterbean, Botanicals, In-vitro

Article Info

Accepted:

20 August 2018

Available Online:

10 September 2018
Clusterbean [Cyamopsis tetragonaloba (L.) Taub], an important legume crop in India. Alternaria spp. is an economically important pathogen widely distributed throughout the world and cause devastating disease on field crops. A total of eight commonly available botanicals were evaluated in the form of crude extracts against the growth of Alternaria cyamopsidis under in-vitro condition. Results of the in vitro evaluation of various botanicals against $A$. cyamopsidis revealed that all the test botanicals significantly inhibited mycelial growth of A. cyamopsidis, over untreated control. Azadirachta indica and Eucalyptus were found most effective followed by Allium cepa, Zingiber officinalis, Parthenium and Datura. While, Lantana camara was found least effective against mycelial growth of Alternaria cyamopsidis. Azadirachta indica and Eucalyptus were significantly superior over all other treatments.

\section{Introduction}

Clusterbean [Cymopsis tetragonaloba (L.) Taub.] has become popular not only for consumption as vegetables but also as good source of useful industrial 'Guar gum' (Reddy et al., 2014). In India, guar cultivation is accounted for about 75 percent of global trade and 80 percent to total guar production in the world (Dhananjaya and Naveena, 2015). In India, clusterbean is being grown in the area of 4.2 million hectares with a production of 2.42 million tonnes of cluster bean seed with an average productivity of $567 \mathrm{~kg} / \mathrm{ha}$ (Anon, 2014). It suffers from several diseases that cause quantitative and qualitative losses, among them Alternaria spp. is an economically important pathogen widely distributed throughout the world and cause devastating disease on field crops.Nonjudicial use of fungicides adds human and environmental hazards.

The crop like clusterbean, ecofriendly and cost effective approaches are the most important and only advisable. Thus, the present investigations were carried out by the available botanicals that may reduce the dependency on fungicides.

\section{Materials and Methods}

The present studies were conducted in the field of College of Agriculture, Gwalior 
during kharif season of 2016. The experiment was laid out in a complete randomized design (CRD) with eight treatments including untreated control and replicated thrice. The botanicals were evaluated through Poisoned food techniques (Nene and Thapliyal, 1979). All the plant products were collected from vicinity of College of Agriculture, Gwalior. For evaluation of plant extract, leaves crude/ rhizome/ seeds/ bulb extract, the plant parts were thoroughly washed in ordinary tap water. The leaves, rhizome and bulb were dried in air and cut into small pieces, then grinded and sieved (100 mesh) and collected into conical flask for further use of investigation. The crude extract was used @ $40 \mathrm{ml}$ solution of the respective botanical crude extract was incorporated into $60 \mathrm{ml}$ Potato sucrose agar medium and pinch of streptomycin sulphate was mixed just before pouring. 7-mm culture discs of Alternaria isolated from guar leaves are to be taken from seven days old colony and placed in the centre of the Petri dishes containing potato dextrose agar and appropriate percentages of plant extracts, without extract medium served as control. The radial growth of the mycelium was measured after 7 days of incubation at $21 \pm 1^{\circ} \mathrm{C}$ and per cent inhibition was calculated using the formula;

$I=\frac{C-T}{C} \times 100$

Where,

$\mathrm{I}=$ per cent inhibition

$\mathrm{C}=$ linear growth in control $(\mathrm{mm})$

$\mathrm{T}=$ linear growth in treatment $(\mathrm{mm})$

\section{Results and Discussion}

A total of eight commonly available botanicals viz., Azadirachta indica, Eucalyptus globulus, Allium cepa, Parthenium hysterophorus, Lantana camara, Datura stramonium and Gingiber officinalis were evaluated in the form of crude extracts against the growth of Alternaria cyamopsidis under in-vitro condition. The fungal growth was recorded at 3,5 and 7 days after inoculation. The data presented in the table 1 clearly indicated that all the botanicals significantly inhibited by the growth of $A$. cyamopsidis under in-vitro condition. Among the tested botanicals, $A$. indica (100\%) and E. globulus (100\%) completely inhibited the growth of $A$. cyamopsidis.

The treatments, A. cepa (91.02\%), G. officinalis $\quad(89.38 \%), \quad$ P.hysterophorus $(80.81 \%)$, D. stramonium $(58.77 \%)$ were found significantly superior in reducing the fungal growth. Minimum inhibition (52.14\%) was found in L. camara. While in control the mycelial growth was maximum $(81.6 \mathrm{~mm})$.

This study reveals that the maximum inhibition of mycelium was observed in Azadirachta indica. The results were supported by Govindachari et al., (1998); Kumar et al., (2005); Singh and majumdar (2001); Ganie et al., 2013. The present findings are similar to the findings of Balai and Ahir, 2011. Azadirachta indica, Allium cepa and A. sativum showed antifungal property against Alternaria alternate.

The extracts of Eucalyptus sp., and Calotropis procera inhibited the growth of fungus (Singh and Kumar, 2011); Nandagopal and Ghewande, 2004). Allium sativum and Allium cepa brought about significant reduction in disease intensity caused by Alternaria leaf spot on the soybean crop (Srikanth et al., 2014; Nguyen, 2013). It is evident from the results that all the botanicals were found effective.

At present, plant extracts are gaining importance in plant disease management practices. These are the cheaper and safer means of disease management which reduce not only toxicity hazards but also present ecofriendly approach in nature. 
Table.1 In-vitro evaluation of botanicals against $A$. cyamopsidis

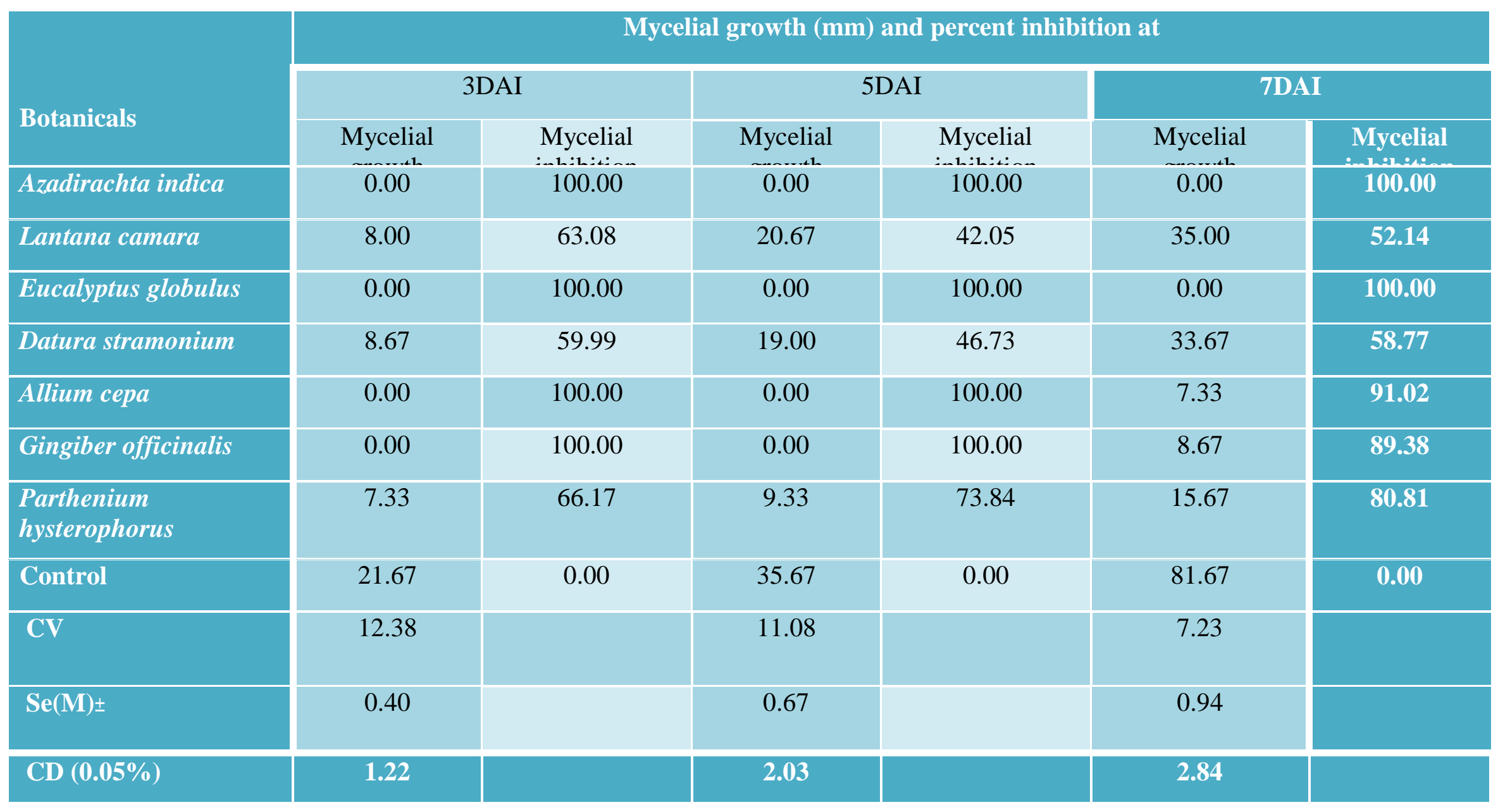




\section{References}

Anonymous, (2014). Agricultural Statistics at a Glance. Ministry of Agriculture, GOI, New Delhi.

Balai Lakshman Prasad and RR Ahir, 2011. Evaluation of plant extracts and biocontrol agents against leaf spot disease. Indian phytopath. 64 (4): 378 380.

Ganie, S.A V.; Pant, R.; Ghani, M. Y.; HussainAshiq Lone, AnjumQaisar and Razvi, S. M. (2013). In vitro evaluation of plant extracts against Alternaria brassicae (Berk.) Sacc. causing leaf spot of mustard and Fusarium oxysporum f. sp. Lycopersici causing wilt of tomato. Sci. Res. Essays. 8 (37): 1808- 1811.

Govindachari, T.R.; Suresh, G.; Geetha Gopalakrishnan; Balaganesan Banumathy; Masilamani, S; Gopalakrishnan, G. and Banumathy, B. (1998). Identification of antifungal compounds from the seed oil of Azadirachta indica. Phytoparasitica., 26(2): 109-116.

Kumar Sanjeet, J P.; Upadhyay and Sanjeev Kumar. (2005). Evaluation of plant extracts for control of Alternaria Leaf spot of Viciafaba. Ann. Pl. Protec. Sci., 13 (1): 213-269.

Nandagopal, V. and Ghewande, M.P. 2004. Use of neem products in groundnut pest management in India. Natural Product Radiance. 3(3): 150-155.

Nene, Y.L. and Thapliyal, P.N. (1993).Evaluation of fungicides in plant disease control (3rd ed.). Oxford, IBH Publi., New Delhi (India).

Nguyen Khanh Ngoc. (2013). In vitro evaluation of botanicals, bioagents and fungicides against Alternaria solani causing early blight on tomato. 47(1): $180-183$ ref.5

Reddy, D. S., Nagare, P.K., Reddaiah, K. and Reddy, B. R. (2014). Effect of integrated nutrient management on growth, yield, yield attributing characters and quality characters in clusterbean (Cyamopsis tetragonoloba (L.) Taub.). The Ecoscan. 4: 329-332.

Singh, J. and Majumdar, V.L. 2001. Efficacy of plant extracts against Alternaria alternata - the incitant of fruit rot of pomegranate (Punica granatum L.). $J$. Mycol. Pl. Path. 31: 346-349.

Singh, P.K. and Kumar Vijay, (2011). Effectiveness of plant extract in controlling wilt pathogen of Chrysanthemum. Bioscience Discovery.2 (2): 232-235.

Sri kanth B Bhosale, D.S. Jadav, B.Y. Patil, Ashok, M. Chavan. (2014), Bio efficacy of plant extract on Alternaria leaf spot of soybean (Glycine $\max ($ L.) Merr). Indian J. applied res., $4-11$.

\section{How to cite this article:}

Manasa Yedida and Reeti Singh. 2018. In vitro Evaluation of Botanicals against Alternaria cyamopsidis causing Alternaria blight of Clusterbean. Int.J.Curr.Microbiol.App.Sci. 7(09): 3060-3063. doi: https://doi.org/10.20546/ijcmas.2018.709.381 